\title{
The Mathematics and Science Teacher Shortage: Fact and Myth
}

\author{
By \\ Richard M. Ingersoll \\ and \\ David Perda
}

The Consortium for Policy Research in Education includes:

University of Pennsylvania Teachers College Columbia University Harvard University Stanford University

University of Michigan University of Wisconsin-Madison Northwestern University 


\section{Consortium for Policy Research in Education}

The Consortium for Policy Research in Education (CPRE) unites seven of the nation's leading research institutions to improve elementary and secondary education through research on policy, finance, school reform, and school governance. Members of CPRE are the University of Pennsylvania, Teachers College Columbia University, Harvard University, Stanford University, the University of Michigan, the University of Wisconsin-Madison, and Northwestern University.

CPRE is currently examining how alternative approaches to education reform--such as new accountability policies, teacher compensation, whole-school reform approaches, and efforts to contract out instructional services--address issues of coherence, incentives and capacity. The results of this research are shared with policymakers, educators, practitioners, and other interested individuals and organizations in order to promote improvements in policy design and implementation.

\section{CPRE Research Report Series}

Research Reports are issued by CPRE to facilitate the exchange of ideas among policymakers, practitioners, and researchers who share an interest in education policy. The views expressed in the reports are those of individual authors, and are not necessarily shared by CPRE, or its institutional partners.

For more information, visit our website www.cpre.org, or call us at (215) 573-0700. 


\title{
The Mathematics and Science Teacher Shortage: Fact and Myth ${ }^{1}$
}

By

\author{
Richard M. Ingersoll \\ and \\ David Perda
}

University of Pennsylvania

March, 2009

CPRE Research Report \#RR-62

\footnotetext{
${ }^{1}$ This research was supported by a grant (\# 0455744) from the Teacher Professional Continuum Program of the National Science Foundation. Opinions in this paper reflect those of the authors and do not necessarily reflect those of the granting agency, CPRE, or its institutional partners. This article draws from earlier papers presented at the Teacher Supply and Demand Symposium at the National Center for Education Statistics, March, 2007, Washington, DC, and the National Commission on Teaching and America's Future Symposium on the Scope and Consequences of K12 Science and Mathematics Teacher Turnover, October, 2006, Wingspread Conference Center, Racine, WI. Thanks are due to Dan McGrath, Ellen Behrstock and Tom Carroll for helpful comments on earlier drafts.
} 


\begin{abstract}
Contemporary educational thought holds that one of the pivotal causes of inadequate school performance is the inability of schools to adequately staff classrooms with qualified teachers, especially in fields such as mathematics and science. Shortages of teachers, it is commonly believed, are at the root of these staffing problems, and these shortfalls are, in turn, primarily due to recent increases in teacher retirements and student enrollments.

The objective of this study is to empirically reexamine the issue of mathematics and science teacher shortages and to evaluate the extent to which there is a supply-side deficit-a shortage — of new teachers in these particular fields. The data utilized in this investigation are from three sources - the Schools and Staffing Survey and its supplement, the Teacher Follow-Up Survey; the Integrated Postsecondary Educational Data System; and the Baccalaureate and Beyond Survey, all conducted by the National Center for Education Statistics.

The data show that there are indeed widespread school staffing problems - that is, many schools experience difficulties filling their classrooms with qualified candidates, especially in the fields of math and science. But, contrary to conventional wisdom, the data also show that these school staffing problems are not solely, or even primarily, due to shortages in the sense that too few new mathematics and science teachers are produced each year. The data document that the new supply of mathematics and science teachers is more than sufficient to cover the losses of teachers due to retirement. For instance, in 2000 there were over two and half teachers in the new supply of math teachers for every one math teacher who retired that year. However, when preretirement teacher turnover is factored in, there is a much tighter balance between the new supply of mathematics and science teachers and losses. The data also shows that turnover varies greatly between different types of schools and these differences are tied to the characteristics and conditions of those schools. While it is true that teacher retirements are increasing, the overall volume of turnover accounted for by retirement is relatively minor when compared with that resulting from other causes, such as teacher job dissatisfaction and teachers seeking to pursue better jobs or other careers.
\end{abstract}




\section{The Mathematics and Science Teacher Shortage: Fact and Myth}

\section{Introduction}

Few educational problems have received more attention in recent years than the failure to ensure that all elementary and secondary classrooms are staffed with qualified teachers. At the root of these school staffing problems, we are told, is a dramatic increase in the numbers of additional teachers needed, primarily resulting from two converging demographic trendsincreasing student enrollments and increasing teacher turnover caused by a "graying” teaching force. We have been warned repeatedly that our teacher preparation institutions are not producing sufficient numbers of teachers to cover losses due to teacher retirement. The resulting teacher shortage crisis, this thesis continues, is forcing many school systems to lower standards to fill teaching openings, in turn inevitably leading to high levels of underqualified teachers and lower school performance.

Researchers and policy analysts have stressed that these shortfalls affect some teaching fields more than others. Mathematics and science, in particular, are typically targeted as fields most suffering from shortages (e.g., Murnane et al., 1991; Grissmer \& Kirby, 1992, 1997; Weiss \& Boyd, 1990; National Commission on Mathematics and Science Teaching, 2000; Liu et al. 2008).

Concerns over teacher shortages, especially for mathematics and science, are not new to the K-12 education system. In the early and mid 1980s a series of highly publicized reports trumpeted an almost identical series of claims and concerns (see, e.g., National Commission on Excellence in Education, 1983; Darling-Hammond, 1984; National Academy of Sciences, 1987; for reviews of this issue, see Boe \& Gilford, 1992). Indeed, teacher shortages historically have been a cyclic concern in the educational system (Tyack, 1974; Weaver, 1983).

However, in recent years concern over shortages, especially in mathematics and science, has seemed to reach new heights. Numerous high-profile reports from organizations including the National Academy of Sciences (2006), the National Research Council (2002), and the U.S. Department of Education (2002) have directly tied mathematics and science teacher shortages to the quality of educational performance and, in turn, to the future well-being of the economy and the security of the nation. As a result, the inability of schools to adequately staff classrooms with 
qualified teachers has received widespread coverage in the national media, has been heralded as a major educational problem, and has been the target of numerous reform and policy initiatives.

Throughout, commentators, researchers, and reformers almost invariably use the term shortage in a generic sense to refer to any school staffing problems, that is, to any difficulties that schools encounter adequately staffing classrooms with qualified teachers. In turn, commentators, researchers, and reformers almost invariably assume that the roots of these school staffing problems primarily lie in an inadequate supply of new teachers: That is, the term shortage, in the context of teachers and schools, almost always connotes an insufficient production of new teachers.

Accordingly, the prevailing policy response to these school staffing problems, both now and in the past, has been to attempt to increase the quantity of new teachers supplied. In recent years, a wide range of initiatives has been implemented to recruit new candidates into teaching. Among these are career-change programs, such as "troops-to-teachers," designed to entice professionals into midcareer switches to teaching, and Peace Corps-like programs, such as Teach for America, designed to lure the "best and brightest” into understaffed schools. Many states have instituted alternative certification programs, whereby college graduates can postpone some or all of their formal education training and begin teaching immediately. Some school districts have resorted to recruiting teaching candidates from overseas. Financial incentives, such as signing bonuses, student loan forgiveness, housing assistance, and tuition reimbursement, have all been instituted to aid recruitment (see, Hirsch et al., 2001; Feistritzer, 1997; Rice et al., 2008; Liu et al. 2008). These initiatives often have been targeted to mathematics and science. In his 2006 State of the Union address, for instance, President Bush specifically called for the recruitment of 30,000 new mathematics and science teachers. The federal No Child Left Behind Act (NCLB) provides extensive funding for such initiatives.

Concern over shortages also has spurred empirical research on teacher supply and demand (e.g., US Department of Education, 2008; American Association for Employment in Education, 2007). But, research on teacher supply and demand has suffered from serious limits of both data and methods. There are few sources of comprehensive data, especially at a nationally representative level, on the supply of qualified teachers. Among the problems confronting the collection of comprehensive data on teacher supply is the character of the teaching occupation itself. Entry, licensing, and preemployment preparation for the teaching 
occupation are relatively decentralized and dispersed in the United States, compared with other nations and also compared with other occupations in this country (Ingersoll, 2004, 2007). ${ }^{2}$ As a result, teaching has relatively wide and multiple entry “gates” (Etzioni, 1969; Lortie, 1975). This has implications for data and research.

Many observers assume the main, or even sole, source of new hires is the "pipeline" of college students who have recently completed a traditional teacher-preparation program in a school of education and obtained a teaching certificate. But, this overlooks several other supply sources of new hires in schools. First, there are an increasing number of alternative and nontraditional routes into teaching. Moreover, in addition to the pipeline of newly qualified candidates (regardless of whether through a traditional or nontraditional route), there is what is referred to as the "reserve pool.” This includes those who completed teacher preparation in prior years, but who never taught, as well as former teachers who left teaching to later return. Finally, a third and large source of new entrants to particular schools is, of course, other schools- those who are already employed as teachers who move from one school to another.

Perhaps because of these data limits, much of the research, commentary, and writing on teacher shortages have not been theoretically or empirically well grounded. For instance, researchers have rarely specified how to evaluate whether teacher supply and demand are, or are not, in balance and how to empirically determine at what point teacher supply is, or is not, sufficient to meet the demand for teachers. Although it is widely assumed that teacher losses from retirement far outstrip the production of new teachers, there have been few, if any, attempts to empirically test this claim, especially with nationally representative data. Moreover, there have been few efforts to investigate whether the staffing problems of schools could be a result of factors other than inadequate production of new teachers.

\footnotetext{
2. Our use of the terms occupation and profession is not normative, but analytic, and derives from the sociology of occupations and professions. From this theoretical perspective, professions are an elite subset of occupations characterized by rigorous training and licensing requirements, self-governance, substantial workplace authority, relatively high compensation, and prestige. Attorneys, physicians, professors, architects, scientists, dentists, and engineers, in particular, usually are classified as the "traditional” professions. In this perspective, elementary and secondary teaching has been classified as a "semiprofession” (see, Etzioni, 1969; Ingersoll \& Perda, 2008).
} 


\section{The Study}

This study reexamines the mathematics/science teacher shortage thesis. Our objective is to empirically ground the debate over teacher shortages and to evaluate the extent to which there is a supply-side deficit—a shortage — of new teachers in these fields. This study builds on our prior research on teacher supply and demand. In this earlier work, we have offered an alternative perspective to the contemporary teacher shortage thesis to explain the staffing problems that plague schools (see Figure 1) (for summaries, see Ingersoll, 2001, 2003). Our analyses revealed that preretirement teacher turnover - the departure of teachers from their schools-is a significant factor behind the demand for new hires and the accompanying difficulties that schools encounter staffing classrooms with qualified teachers. In turn, we documented that teacher turnover varies greatly between different kinds of schools and is closely tied to the organizational characteristics and working conditions of those schools. Unlike research on employee turnover in other industries, there has been little empirical investigation of the types and amounts of costs and benefits, advantages, and disadvantages of teacher turnover. ${ }^{3}$ Our alternative perspective reveals that one cost and consequence of teacher turnover is its connection to the larger staffing problems and shortages that plague the educational system. Hence, from a policy perspective, the data suggest that improving teacher retention is an important, but largely overlooked, antidote to school staffing problems.

Figure 1. Two Perspectives on the Causes and Consequences of School Staffing Problems.

The teacher shortage thesis:

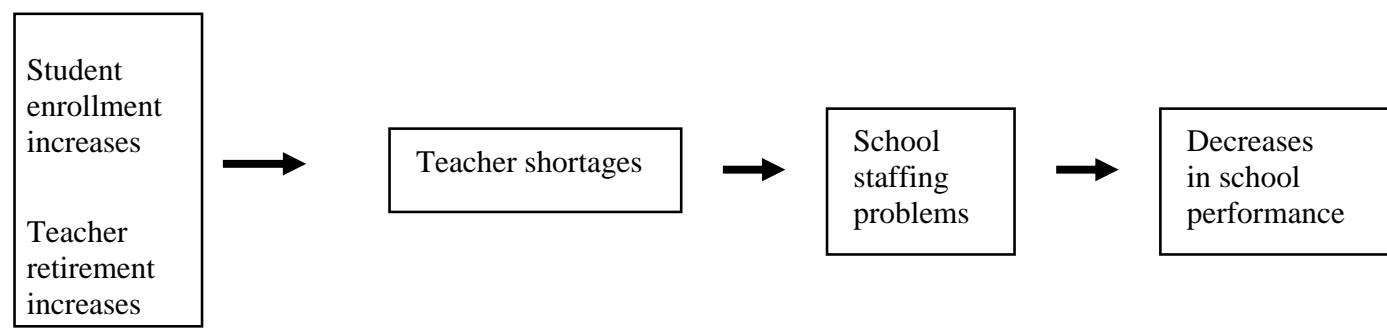

An organizational perspective:

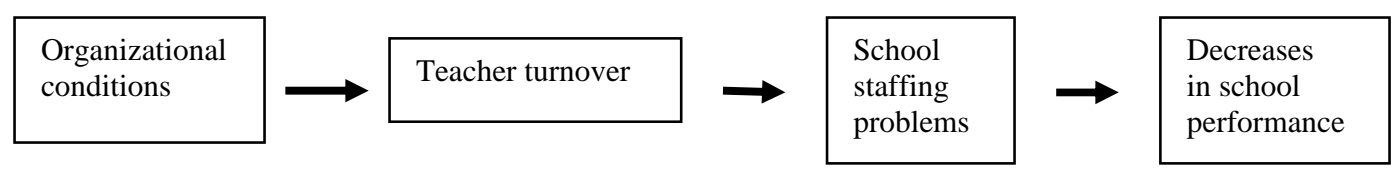


One limitation of our earlier work was that we examined the teaching force as a whole and did not investigate field-to-field differences in shortages and turnover. We did not specifically and empirically examine the widely held view that there is indeed a supply-side deficit - a shortage — of new teachers in particular fields, such as mathematics and science. Nor did we test whether our alternative perspective, focusing on preretirement turnover, applies to particular fields such as mathematics and science. These are the objectives of this new study.

In this project we build on our previous work by disaggregating the data and comparing different fields. Specifically, we focus on and compare the data for mathematics and science, considered shortage fields, with the data for other kinds of teachers, especially for English, typically considered a surplus field. One of the contributions of this new study is that we have collated and analyzed comprehensive national data on the actual quantity of new qualified teachers supplied from different sources, by field, and analyzed data on the actual quantities of teacher retirement and attrition, by field. Such data allow us to empirically evaluate the degree of balance or imbalance between the supply of, and demand for, new mathematics and science teachers, which is - to our knowledge - a data analysis not done before.

A second and related set of issues not fully addressed in the extant research has to do with how high teacher turnover really is and how much of a problem it poses for schools. How do rates of teacher turnover compare with employee turnover in other occupations and in the professions? What is the magnitude of beginning teacher turnover? This current paper investigates one possible consequence of turnover -staffing problems and shortages. But, there are other possible benefits and costs tied to teacher turnover. We closely examine these questions in a second related paper (see Ingersoll \& Perda, 2009).

\section{Research Questions}

In this study, there are four sets of research questions we seek to address:

\section{(1.) What is the magnitude of demand for new teachers and the magnitude of school} staffing problems? To what extent do schools suffer from teacher staffing problems and hiring difficulties, especially for mathematics and science, in comparison with English? 
(2.) Is the supply of new teachers adequate? What are the main supply sources of new teacher hires for mathematics, science, and English? What are the magnitudes of these sources? What do the data indicate about the adequacy of the supply of new teachers in these fields? Can we empirically evaluate the extent to which there is a supply deficit—a shortage—of new teachers in mathematics and science? Rather than a national issue, are shortages really a problem that is specific to particular locales and states?

(3.) What is the role of teacher turnover in school staffing problems? What portion of the demand for new mathematics, science, and English teachers is accounted for by teachers moving from their schools or leaving teaching? What is the overall magnitude of turnover in these fields? (4.) What are the sources of teacher turnover? What are the reasons behind the turnover of mathematics, science and other teachers? What portion of mathematics and science teacher turnover is due to retirement?

The theoretical perspective we adopt in our research is drawn from organizational theory and the sociology of organizations, occupations, and work. Our operating premise is that in order to fully understand the causes and consequences of school staffing problems, it is necessary to "put the organization back” into the analysis (cf. Stolzenberg, 1978; Baron \& Bielby, 1980), and to examine these issues from the perspective of the schools and districts where these processes happen and within which teachers work. Employee supply, demand, and turnover are central issues in organizational theory and research (e.g., Mobley 1982; Price 1977, 1989; Mueller \& Price 1990; Hom \& Griffeth 1995). However, there have been few efforts to apply this theoretical perspective to understanding staffing problems in education. By adopting this perspective, we seek to show that staffing problems in schools can be reframed from macro-level issues, involving inexorable societal demographic trends, to organizational-level issues, involving manipulable and policy-amenable aspects of particular districts and schools.

In the next section, we define key terms and describe our several data sources. In the following sections of this paper, we present our results sequentially for each of our four research questions. We then conclude by discussing the implications of these findings for understanding and addressing the staffing problems of schools. 


\section{Data and Methods}

To try to provide a more complete and comprehensive understanding of teacher supply, demand and staffing problems, this study utilizes three different nationally representative datasets. All three are based on surveys undertaken by the National Center for Education Statistics (NCES), the statistical arm of the U.S. Department of Education. Fortuitously, these three databases were collected during the same period, allowing us to utilize them in conjunction. Utilizing multiple data sources in conjunction allows us to gain a more comprehensive portrait of teacher supply and demand. Each dataset has individual strengths and limits; by combining them we try to take advantage of the former and compensate for the latter. But utilizing multiple data sources also presents challenges resulting from differences in the data collected and how variables were defined. We discuss these data issues at some length below.

The primary source of data for this study is the Schools and Staffing Survey (SASS) and its supplement, the Teacher Follow-Up Survey (TFS), collected by the Census Bureau for NCES. SASS/TFS is the largest and most comprehensive data source available on the staffing, occupational, and organizational aspects of schools. SASS administers survey questionnaires to a random sample of about 50,000 teachers, 12,000 principals, and 4,500 districts, representing all types of teachers, schools, districts, and all 50 states. NCES has administered SASS on a regular basis; to date, five cycles have been completed-1987-88, 1990-91, 1993-94, 1999-2000, and 2003-04. (For information on SASS, see NCES, 2005.) In addition, all those teachers in the sample who departed from their schools in the year subsequent to the administration of the initial survey questionnaire are contacted to obtain information on their departures. This supplemental sample — the TFS—contains about 7,000 teachers. Unlike most previous data sources on teacher turnover, the TFS is large, comprehensive, nationally representative, includes the reasons teachers themselves give for their departures, and includes a wide range of information on the characteristics and conditions of the schools that employ teachers. It also is unusual in that it does not solely focus on a particular subset of separations, but includes all types of departures. (For information on the TFS, see Chandler et al., 2004.) We use the SASS data to understand the sources, size, and qualifications of the existing employed teaching force. The data analyzed for this study are drawn primarily from the 1999-2000 SASS and represent all teachers for grades prekindergarten through 12, part-time or full-time, and from all types of schools, including public, charter, and private. 
There is a great deal of debate concerning the amounts and kinds of preparation teachers ought to have to be considered qualified in any given field. From an empirical perspective, one's definition of qualified is important because it impacts the number found to be qualified. Here we adopt a major-based definition — roughly equivalent to that of NCLB. We define a teacher as qualified in a given field, such as mathematics or science, if he or she holds an undergraduate degree, or a graduate degree, in that or a related field. We count as qualified both noneducation and subject-area education degrees (e.g., math or math education). Like NCLB, we do not count those with only a college minor in a field as qualified in that field. Moreover, like NCLB, we do not count those with only a teaching certificate in a field as qualified, absent a degree or major in that field. Unlike NCLB, we do not use teachers' test scores as a means of assessing qualifications in a field because our data do not have such information. From an NCLB perspective, not including the latter biases our estimates downward. Moreover, we do not base our definition of qualified teachers on a respondent's teaching assignments, where, for example, a teacher assigned to teach mathematics is assumed to be qualified in mathematics. Identifying teachers according to their fields of preparation differs from identifying teachers according to their fields of assignment. The latter may not be an accurate method of identifying the number of qualified teachers in particular fields because of the widespread practice of out-of-field teaching in which teachers are assigned to teach subjects for which they have few formal qualifications (Ingersoll, 1999). We chose a major-based method of identification because it represents those teachers with a credential signifying human capital in the field and is the subject of policy concern.

As indicated, our emphasis in this study is on the comparison between mathematics, science, and English teachers. Using the SASS data, we define qualified mathematics teachers as those who indicated they had completed an undergraduate or graduate major in mathematics, statistics, mathematics education, or engineering. We define qualified science teachers as those who indicated they had completed an undergraduate or graduate major in science education, biology, physics, chemistry, geology, or another natural science. About $22 \%$ of the mathematics/science teachers are employed in elementary or middle schools, another $73 \%$ are in secondary schools, and about $5 \%$ are in combined (K-12 grades) schools. We define qualified English teachers as those who indicated they had completed an undergraduate or graduate major in English literature, English composition, English education or language arts education. 
We use the TFS data to analyze teacher turnover. The data analyzed for this study are drawn primarily from the 2000-01 TFS. Our analysis distinguishes between two general types of teacher turnover from schools. The first, often called teacher attrition, refers to those who leave teaching altogether. The second type, often called teacher migration, refers to those who transfer or move to different teaching jobs in other schools. Research on teacher supply and demand has often emphasized the first type and deemphasized the second type. Many assume that teacher migration is a less significant form of turnover because it does not increase or decrease the overall supply of teachers, as do retirements and career changes, and hence assume it does not contribute to overall shortages. From a systemic level of analysis, this may be correct. However, from the organizational perspective of this study and from the viewpoint of those managing educational organizations, teacher migration and attrition have the same effect; in either case, it results in a decrease in staff that usually must be replaced. For this reason, research on employee turnover in other occupations and organizations almost always includes both cross-organization movers and occupational leavers (see, e.g., Price, 1977), and for this reason we include both here. Hereafter, we use the term teacher migration interchangeably with the term movers, teacher attrition with leavers, and total turnover with departures.

The SASS/TFS data are useful for understanding the character, size, qualifications, and sources of the existing teaching force, how teachers entered teaching, their movements between and among schools, and their attrition from teaching altogether. SASS and TFS, however, do not provide much information on the pipeline into teaching and the characteristics of the new supply of potential teachers.

In this study we attempt to distinguish and quantify the main sources of new hires in schools. We define new teacher supply as those available and qualified individuals who had not taught the previous year and who are potentially new hires. As we define it, being part of the available new teacher supply does not mean an individual actually seeks or enters employment as a teacher; it means they are qualified to do so. ${ }^{4}$ This new supply includes two components. The first is the pipeline of newly qualified candidates or those actively seeking to be qualified, and includes those entering from traditional, fifth-year, or alternative preparation programs. The

4. Our definition of supply differs from that typically used by labor economists - where supply is defined as the number of those both able and willing. We define teacher supply as the number of those able (i.e. qualified) to teach, in order to distinguish between those qualified and those willing. 
second component comprises the reserve pool, which includes delayed entrants who completed their preparation in a prior year but have not previously taught, and reentrants who taught previously, stopped for a while, and then returned. Other than the pipeline and reserve pool, a third source of new hires to particular schools is represented, of course, by those who are already employed as teachers and move from one school to another.

To obtain national data on the new supply pipeline of qualified teachers, we utilize two additional NCES databases. The first of these data sources is the Integrated Postsecondary Educational Data System (IPEDS). IPEDS is a comprehensive source of data from the universe of postsecondary education providers (For information on this dataset, see NCES, 2003). For our purpose we focus on the IPEDS data concerning an important part of the pipeline- those who complete both undergraduate and graduate degrees in education. We utilize data from the 19992000 IPEDS cycle to coincide with data from the 1999-2000 SASS data. We focus, in particular, on those who completed degrees at the end of that year in the fields of: mathematics education, science education, biology education, chemistry education, physics education, and English education.

One limitation of the IPEDS database on degree completions is that it does not include recipients of noneducation degrees who seek to become teachers - an important component of the teacher supply pipeline. Data on this latter component come from our final data source-the 2000-2001 Baccalaureate and Beyond Survey (B\&B). This survey collected data from a nationally representative sample of 10,030 new recipients of undergraduate bachelor's degrees who graduated during or at the end of the 1999-2000 academic year (For information on this dataset, see NCES, 2004). This cohort sample was interviewed at the end of their senior year in college and a year later in July, 2001.

The B\&B obtained information on new recipients of noneducation undergraduate degrees who entered the pipeline to become teachers prior to, or in the year immediately after, their graduation. We focus, in particular, on those among this group who completed noneducation degrees in mathematics, engineering, the biological sciences, the physical sciences (physics, chemistry, earth science), and English. We count noneducation degree completers as being in the teacher supply pipeline if they met one or more of the following criteria: (a) They obtained a teaching certificate during their senior year or immediately after their graduation; (b) within a year of graduation, they took a national or state teacher licensure exam; (c) within a year of 
graduation, they applied for a teaching job; or (d) within a year of graduation, they actually began teaching. We do not include in our pipeline count those undergraduates who indicated in the B\&B survey questionnaire that they had "considered working as a teacher," but then did not pursue this in any of the above ways. Unlike IPEDS, the 2000-01 B\&B database did not include graduate-level degree completions, which slightly biases our supply estimates downward.

However, neither the IPEDS nor the B\&B includes two relevant supply sources. First, they do not capture all of those who enter teaching through a nondegree, nontraditional route undertaken more than one year after graduating from college. Hence, midcareer switchers are sometimes excluded. Moreover, neither provides information on the size and characteristics of the reserve pool. While we know of no national data on the reserve pool, there is reason to assume it is very large. We have found in our analyses of the B\&B data that large proportions of recipients of education degrees, who are fully qualified to teach, and could teach, do not do so a finding also documented by other analyses of those data (e.g., Henke et al., 2000). Moreover, as the analysis in this study will show, there are large numbers of teachers who leave teaching prior to retirement. At least a portion of both of these groups ostensibly are part of the teacher supply reserve pool.

Hence, our data on the new teacher supply are biased downward and provide underestimates of the total new teacher supply for several reasons. Our data on the pipeline exclude those who did not have a major in a field, but were qualified in a field by virtue of passing a test. Our data exclude new recipients of noneducation graduate-level degrees who entered the pipeline to become teachers. Our data exclude midcareer entrants who came through nondegree routes. Most importantly, we do not have data on the number of qualified candidates in the reserve pool. The implications of this downward bias, however, will differ according to what we find in our analyses to follow. Given our underestimates, a finding that the new supply of teachers is sufficient would be strengthened, while a finding that the new supply of teachers is insufficient would be weakened.

\section{Results}

What Is the Magnitude of Demand for New Teachers and the Magnitude of School Staffing Problems?

Data from SASS/TFS show that number of teachers has increased in recent years and that most schools have had job openings for teachers in any given year. As shown in Table 1, since 
the early 1990s, student enrollments have increased (Row 1), although the rate of these student enrollment increases declined slightly throughout the 1990s, the number of teachers hired has increased (Row 2), and the size of the teaching workforce (K-12) has increased (Row 3). 
Table 1. Trends in Student Enrollments, the Teaching Force, and Teacher Flows In and Out of Schools.

School Year

\begin{tabular}{|c|c|c|c|c|c|}
\hline & 1987-88 & 1990-91 & 1993-94 & 1999-2000 & 2003-04 \\
\hline 1) Total student enrollment (K-12) & $45,220,953$ & $44,777,577$ & $46,592,207$ & $50,629,075$ & $52,375,110$ \\
\hline 2) Total teacher hires - at beginning of school year & 361,649 & 387,807 & 377,135 & 534,861 & 537,001 \\
\hline 3) Total teaching force - during school year & $2,630,335$ & $2,915,774$ & $2,939,659$ & $3,451,316$ & 3,717,998 \\
\hline (a) Percent of teachers age 50 or older & $20.1 \%$ & $22.7 \%$ & $24.6 \%$ & $29.3 \%$ & $33.1 \%$ \\
\hline 4) Total teacher turnover - after end of school year & 390,731 & 382,879 & 417,588 & 546,247 & 621,427 \\
\hline (a) Retirees & 35,179 & 47,178 & 50,242 & 66,788 & 87,271 \\
\hline
\end{tabular}

Note: The data in Rows 2 and 4 are calculated at the level of the school. Hires and turnover refer to those newly entering or departing a particular school. Cross-school transfers within districts are counted as hires or as turnover. Within-school reassignments are not counted as either hires or turnover. 
The data also show that there has been an aging of the teaching force. The percentage of teachers 50 years or older has increased (Row 3:A), and the number of teacher retirements has increased (Row 4:A). Our background analyses of the SASS/TFS data indicate that the modal age of retirement for teachers is 59 and the modal age of the teaching force in 2003-04 was 52. This suggests that the numbers of teachers retiring will continue to increase until the 2010-11 school year, after which the numbers will begin to decline.

But, data from the SASS/TFS in Table 1 also show that retirees comprise a relatively small portion of the total teaching force-less than $2 \%$ in any given year. Moreover, this appears to have been consistent over the past four decades. Data from the National Education Association's Status of the American Public School Teacher Survey show that the percent of teachers who reported they expect to retire the following year has stayed at about 2\% since 1966 (National Education Association, 2001, p. 21).

\section{Figure 2: Percent Secondary Schools with Vacancies and with Serious Difficulties Filling those Teaching Vacancies, by Field (1999-2000).}

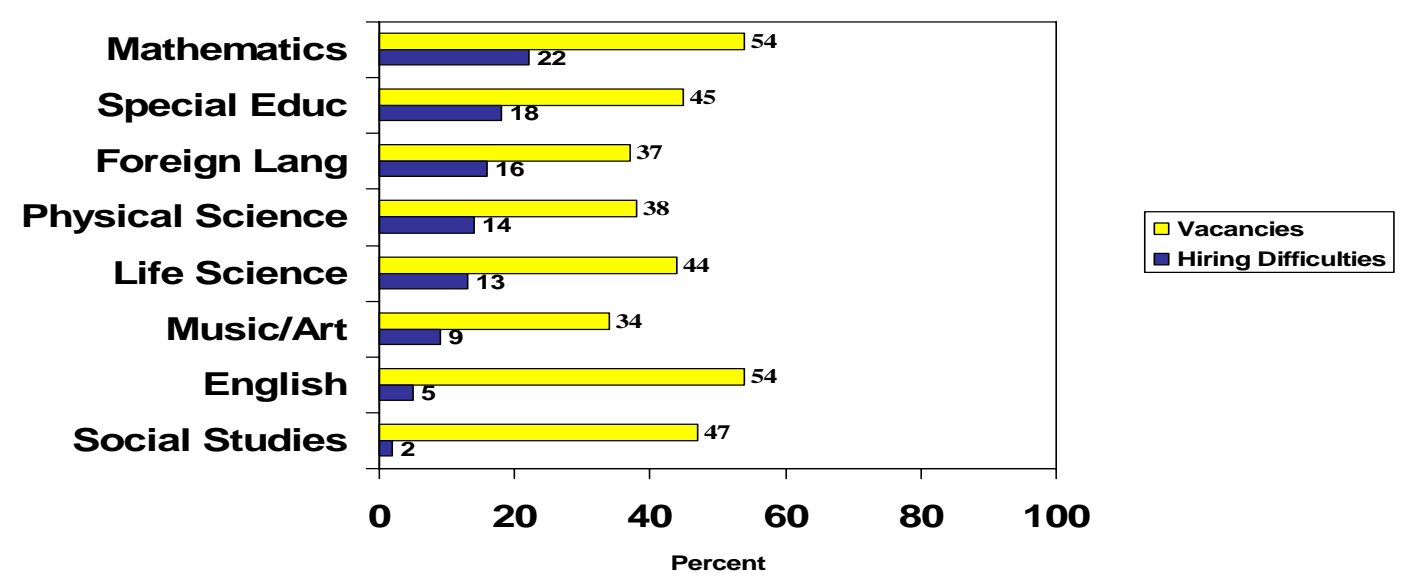

In addition to this increase in demand for additional teachers, and importantly for our analysis, the SASS data indicate that a substantial number of school principals have reported they have had staffing problems in their schools; that is, they reported experiencing difficulties with filling their teaching job openings. Overall, the data show that in the 1999-2000 school year, 
just over half-58\%—of all schools reported that it was at least "somewhat difficult" filling one or more teaching job openings in one or more fields, and 35\% indicated it was either "very difficult" or they "could not fill” one of more openings.

Moreover, as expected, the data also show large field-to-field differences in hiring difficulties (see Figure 2). For instance in the field of English, at the beginning of 1999-2000, $54 \%$ of secondary schools had job openings, but only about $1 / 10^{\text {th }}$ of these-representing $5 \%$ of all secondary schools—indicated that it was "very difficult" or they "could not fill" these openings. ${ }^{5}$ On the other hand, for physical science, $38 \%$ of secondary schools had job openings for teachers in this field and about $37 \%$ of these indicated serious difficulties filling these openings, representing $14 \%$ of secondary schools. Of the eight fields represented, mathematics experienced among the most serious hiring and recruitment problems: $54 \%$ of secondary schools had job openings for mathematics teachers and about $41 \%$ of these indicated serious difficulties filling these openings, representing about $22 \%$ of all secondary schools. In total, the data show that about $31 \%$ of secondary schools had serious hiring difficulties in either mathematics, life sciences, or the physical sciences. In each of these fields there were significantly more schools reporting hiring difficulties than in English, at a statistically significant level $(\mathrm{p}<.05)$. Notably, our analyses also show large school-to-school differences in these hiring difficulties.

What is not clear, thus far, are the sources of, and reasons for, both the apparent increases in demand for new teachers and in the accompanying hiring and staffing difficulties—a question to which we turn in the next several sections.

\section{Is the Supply of New Teachers Adequate?}

While demand for new teachers has increased and many principals have reported hiring difficulties, what do the data indicate about whether there is, or is not, a sufficient supply of teachers? Table 2 provides data from all three of our sources to address this question. It is similar to Table 1, but focuses in more detail on one school year-1999-2000 — and focuses on three

5. The 1999-2000 SASS school questionnaire asked school officials "how difficult or easy it was to fill the vacancies for this school year” in each field. Answers were on a 4-point scale: easy; somewhat difficult; very difficult; could not fill. In Figure 2, we counted as having "serious” difficulty those schools reporting either "very difficult” or "could not fill.” 
specific fields - mathematics, science, and English. It presents data on the flows of new hires into schools at the beginning of that school year, the size of the teaching force at midpoint in the school year, the departures of teachers from schools after the end of that school year, and the new teacher supply pipeline produced by the end of that same year.

Reading down the first column for “All” teachers, Table 2 indicates there were just under 3.5 million teachers in the K-12 education system in the 1999-2000 school year, including public, charter, and private schools. About 535,000 of these teachers entered their schools at the beginning of the school year (Row 1). Of these, 232,231 were new entrants who had not taught the prior year. This latter group includes those from the pipeline of newly qualified entrants from preparation programs (Row 1:A:i) and entrants from the reserve pool (Rows 1:B:i + B:ii). The reserve pool includes delayed entrants who had completed their preparation in a prior year but had not previously taught, and reentrants who had taught previously, stopped for a while, and then returned. While the SASS data cannot indicate how large the reserve pool is, these data do reveal the importance of the reserve pool as a source of supply, as far more new hires come from the reserve pool than directly from preparation programs and higher education institutions. This is an important finding and reemphasizes a point made earlier - that some observers incorrectly assume the pipeline is the main source of new teachers. Another 302,630 of the total hires to schools were movers - that is, they moved from another school (Row 1:C).

By the following school year, 546,247 teachers had moved from their school jobs or left teaching (Row 3). Just under half of these total departures-268,642 — moved to other schools to teach (Row 3:A). Another 277,605 left teaching altogether (Row 3:B). Of the latter, 66,788 were retirees. Simultaneously, at the end of the 1999-2000 academic year, there were 189,554 new recipients of education degrees, at either the undergraduate or graduate level (Row 4:A), and another 250,682 new recipients of noneducation degrees at the undergraduate level, who completed the requirements for a teaching certificate, or took a national or state teacher exam, or applied for teaching jobs, or who actually taught immediately after graduating (Row 4:B). The estimates in Rows $4 \mathrm{~A}+\mathrm{B}$ represent the new teacher supply pipeline.

How can we use these data to empirically evaluate whether there is, or is not, a shortage and whether teacher supply and demand are, or are not, in balance? At what point can we 
Table 2. Teaching Hires, Turnover and Supply - 1999-2000.

\begin{tabular}{|c|c|c|c|c|c|}
\hline & All & English & Science & Math & Source \\
\hline 1) Total teacher hires - at beginning of 1999-2000 year & 534,861 & 50,920 & 35,382 & 29,188 & SASS \\
\hline \multicolumn{6}{|l|}{ (a) New teacher supply from pipeline: } \\
\hline (i) Newly qualified entrants - from programs, with no experience & 90,837 & 9,722 & 6,261 & 5,104 & SASS \\
\hline \multicolumn{6}{|l|}{ (b) New teacher supply from reserve pool: } \\
\hline (i) Delayed entrants - with no teaching experience & 61,642 & 5,952 & 4,909 & 1,776 & SASS \\
\hline (ii) Reentrants - with prior teaching experience & 79,751 & 6,712 & 5,505 & 4,418 & SASS \\
\hline (c) Movers from other schools & 302,630 & 28,534 & 18,577 & 17,891 & SASS \\
\hline 2) Total teaching force - during 1999-2000 year & $3,451,316$ & 308,632 & 223,080 & 182,456 & SASS \\
\hline 3) Total teacher turnover - after end of 1999-2000 year & 546,247 & 48,450 & 39,979 & 28,166 & TFS \\
\hline (a) Movers - to other schools & 268,642 & 25,003 & 18,352 & 14,416 & TFS \\
\hline (b) Leavers - from occupation (including retirees) & 277,605 & 23,447 & 21,627 & 13,750 & TFS \\
\hline (i) Retirees & 66,788 & 7,100 & 3,935 & 3,915 & TFS \\
\hline 4) Total new teacher supply in pipeline - at end of 1999-2000 year & 440,236 & 23,425 & 13,684 & 8,021 & PEDS/B\&B \\
\hline (a) Education Bachelor's and Master’s & 189,554 & 3,313 & 2,390 & 2,173 & IPEDS \\
\hline (b) Noneducation Bachelor's - and exam, certified, applied, or taught & 250,682 & 20,112 & 11,294 & 5,848 & $\mathrm{~B} \& \mathrm{~B}$ \\
\hline
\end{tabular}


determine whether new teacher supply is sufficient, or insufficient, to meet the demand for new teachers? One criterion to partly address these questions is to calculate the employment rate-the ratio of the quantity of new candidates produced to the quantity of these new qualified candidates actually hired by schools. This addresses the question: How much of the new supply ends up actually employed in schools? ${ }^{6}$

Another criterion is to calculate the replacement rate — the ratio of the quantity of new candidates being supplied to the quantity of those permanently leaving teaching, for instance, because of retirement. This addresses the question: Is the new supply sufficient to replace those losses? On the one hand, if the quantity of new candidates is smaller than the losses through attrition, then it suggests that there is not sufficient new supply. On the other hand, if the quantity of new candidates is larger than the losses through attrition, then it makes the case that there is sufficient supply, especially given that the data in Table 2 underestimate the total supply. This part of our analysis focuses solely on attrition and does not include migration.

Using the first of the above criteria, Table 2 shows there were over 440,000 degree holders produced at the end of the 1999-2000 year who were eligible to teach or had entered the pipeline to teach (Row 4). Data on the number of these candidates actually hired for the following school year (2000-2001) are not available, but, the data in Table 2 do show that only about 91,000 (Row 1:A:i) of those hired at the beginning of that same school year (1999-2000) were drawn from an analogous pool of recent degree or preparation program completers. The above data suggest that large proportions of those who originally prepare to become teachers do not actually become employed teachers_-a finding born out by other data. For example, our analyses of the earlier 1993 Baccalaureate and Beyond Survey show that, of new recipients of bachelor of education degrees who graduated in 1993, after one year out of college only $42 \%$ had taught and after four years out of college only 58\% had taught.

6. Note, our objective is not to address the question of whether the supply of teachers is optimal - which entails determining desired class sizes, courseload, etc. Our focus is on whether or not the existing new supply is sufficient to cover losses. Also, see note \#4. 
Moreover, the data in Table 2 also show that the new supply of teachers easily replaces the loss of existing teachers through attrition — the second of our above two criteria. While over 440,000 new candidates were produced in the pipeline at the end of the 1999-2000 year (Row 4), only about 277,000 left teaching at the end of that same year (Row 3:B), and of these only about 67,000 did so because of retirement (Row 3:B:i). In short, the data in the first column of Table 2 appear to indicate that, overall, there are more than enough prospective teachers produced each year in the United States. This conclusion is further strengthened given that we have not counted the reserve pool, which comprises a large proportion of the supply of new hires (Rows 1:B:i + B:ii).

But, there are some important limitations to the data in the first column of Table 2. An overall surplus of new teachers does not, of course, mean there are sufficient numbers of graduates produced in each field. The IPEDS data show that a large proportion of education degree completions are in fields such as elementary education, English, and social studies. The data discussed thus far do not clarify whether there is a sufficient quantity of teachers supplied each year in fields such as mathematics and science-our objective. The additional columns in Table 2 address this question by presenting similar data disaggregated for three fields—English, science, and mathematics.

The English column in Table 2 shows that at the end of the 1999-2000 year, there were just over 23,000 degree holders produced who were eligible to teach English (Row 4). This includes about 3,000 English education majors, and a much larger number of English majors $(20,112)$ who pursued teaching and are counted in the English pipeline. Only about 9,700 (Row 1:A:i) of those hired at the beginning of that same school year (1999-2000) were drawn from an analogous pool of recent degree completers. Moreover, this new supply of 23,425 English teachers was over three times the number of English teachers who retired $(7,100)$ (Row 3:B:i) and about the same as the number of those who left teaching at the end of that same year $(23,447)$ (Row 3:B). We use these data for English as a benchmark with which to assess science and mathematics.

Table 2 shows that, in contrast to English, significantly fewer potential science teachers were produced at the end of the 1999-2000 academic year-13,684. Again, the data suggest that 
much of this new supply is not utilized as teachers in schools. Moreover, this supply of new science teaching candidates (including education or academic degrees in general science, biology, chemistry, physics, and earth science), was over three times as large as the number of science teachers who retired that same year $(3,935)$, but was smaller than the total number of leavers (21,627). A similar portrait holds for mathematics. The 8,021 new mathematics teachers produced at the end of the 1999-2000 year was over twice the number of mathematics teachers who retired $(3,915)$, but was smaller than the number of mathematics teachers who left teaching that year $(13,750)$.

Derived from Table 2, Figure 3 extends and illustrates this last set of findings using four variants of the replacement rate-our second criterion for evaluating the balance of supply to demand. It presents (a) the ratios of the quantity of new candidates being produced in the pipeline to the quantity of those retiring; (b) the ratios of the quantity of new candidates being produced to the quantity of all of those leaving teaching altogether, including retirees; (c) the ratios of the pipeline, plus a portion of the reserve pool, to the quantity of those retiring; and finally, (d) the ratios of the pipeline, plus a portion of the reserve pool, to the quantity of all of those leaving teaching altogether. A ratio greater than 1 indicates the supply exceeds the loss; a ratio less than 1 indicates the loss exceeds the supply. 


\section{Figure 3: Ratio of Pipeline to Retirement and to All Leavers, and Ratio of New Supply to Retirement and to All Leavers, by Field (2000)}

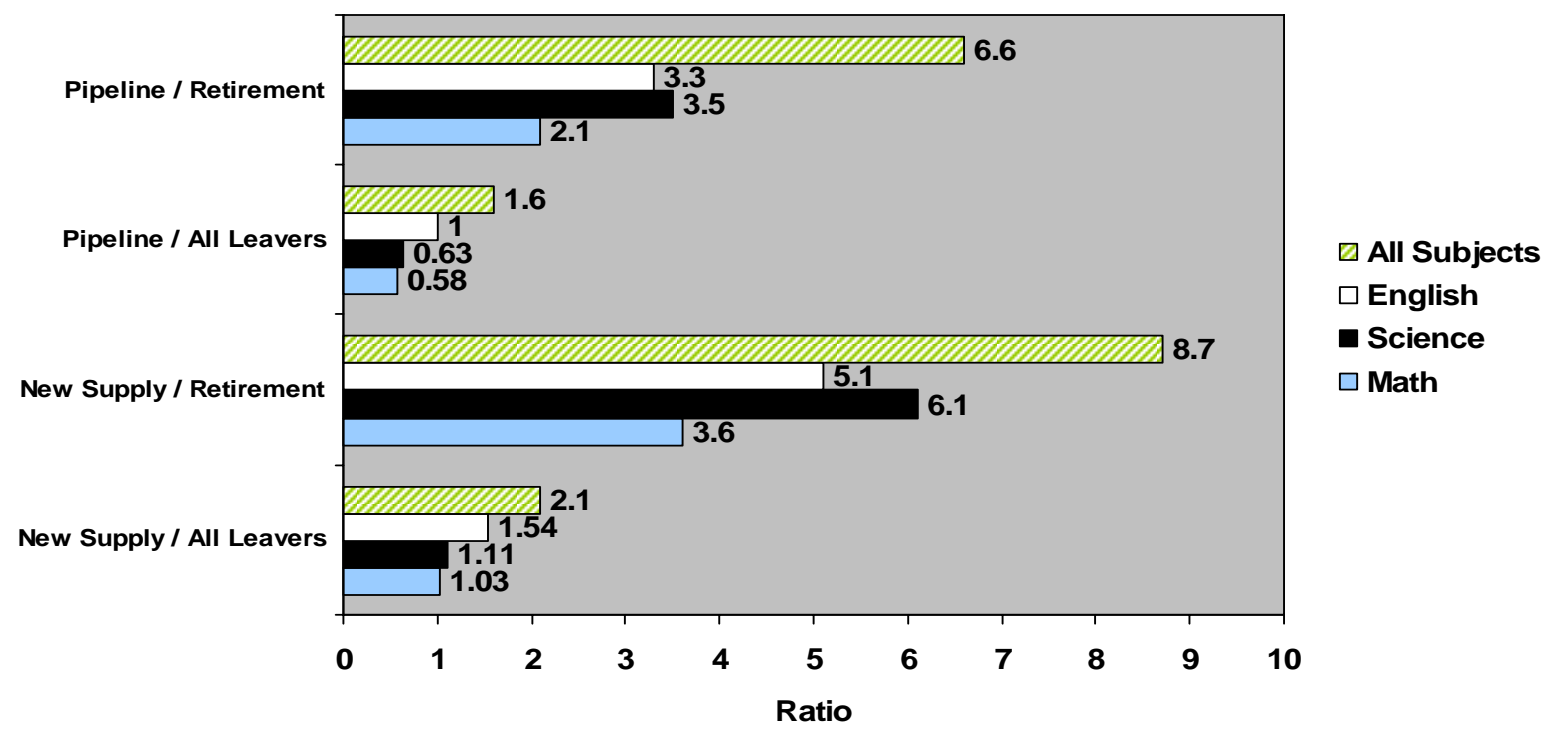

Sources: 2000-01 B\&B; 2000-2001 TFS; 1999-2000 IPEDS

The first set of replacement ratios in Figure 3 illustrates that there were more than enough new candidates in the pipeline alone to replace attrition due to retirement in each field. For instance, there were just over two new mathematics teachers produced for every one mathematics teacher who retired. The second set of ratios shows that for mathematics and science, unlike for English, there was not enough new supply in the pipeline alone to replace all those leaving teaching that year. In other words, for mathematics and science, even if retirement ceased altogether, there would not be sufficient new supply in the pipeline to replace the remaining attrition due to other reasons. Stated another way, there was only about two-thirds of one new science teacher in the pipeline for every science teacher who left teaching.

The third and fourth sets of ratios adds to the pipeline a portion of the other main source of new teacher supply - the reserve pool. We do not know the total magnitude of the reserve pool, but we do know how many were hired from that pool for the 1999-2000 year. Adding this 
portion of the reserve pool to the numerator shows that the overall new supply of teachers is, again more than sufficient to replace retirees. For instance, there were over three and half new mathematics teachers for every one mathematics teacher who retired. Notably, there was also sufficient new supply to replace all attrition - a finding is further strengthened because, as mentioned, our data on the new teacher supply are biased downward and provide underestimates of the total new teacher supply. But, this varies by field and for mathematics and science there was a tight balance. For instance, there were about 1.1 science teachers supplied for every one science teacher to leave teaching.

Of course, a sufficient supply of qualified science teachers does not mean there are sufficient numbers of teachers qualified in each of the separate disciplines within the multidisciplinary field of science. The IPEDS data show there are almost three times as many degrees completed in the biological sciences as in the physical sciences. Physics, in particular, is a numerically smaller discipline than either biology or chemistry and is often cited as having the most severe shortages (e.g., National Academy of Sciences, 2006). To test the latter claim, we disaggregated the science data displayed in Table 2 and Figure 3, by discipline. For physics, the data show the four variants of the replacement rate were 1.21 for the ratio of the pipeline to retirement, .52 for the ratio of the pipeline to all attrition, 2.7 for the pipeline and reserve pool to retirement, and 1.16 for the pipeline and reserve pool to all attrition. In other words, the data showed that, while the ratios for physics were sometimes lower than for science as a whole, there was a sufficient supply of qualified physics teachers to replace losses.

However, the latter data for physics must be interpreted with caution. Many of those who prepare to become science teachers obtain a degree in science education. Often these degrees require recipients to concentrate or major in one or two of the specific science disciplines. However, none of our data sources (IPEDS, B\&B, and SASS) allows us to determine in which of the science discipline(s) these science education degree holders were qualified. This could introduce error into both the numerators and denominators of our ratios. It is, however, worth noting that at least one detailed analysis of state-level data — for Pennsylvania—on the adequacy of teacher supply also concludes that teacher supply is sufficient, even in physics (see Strauss et al., 2008). 
Tables 1 and 2 also provide a context to interpret the widely used statistic that the nation “will need to hire at least two million teachers over the next ten years.” This statistic was drawn from an NCES analysis (Gerald \& Hussar, 1998; Hussar, 1998) that projected the numbers of teachers who would need to be hired from 1998 to 2008 in order to replace those who had left teaching and to account for student enrollment increases. The NCES analyses themselves did not examine supply nor evaluate these projections in a larger context. But, a wide variety of commentators, researchers, and policy analysts have interpreted this statistic to mean that hiring 2 million new teachers over a 10-year period is atypical, an unusually large number and assumed to be evidence that the nation faces an alarmingly inadequate supply of new teachers being produced.

The data in Tables 1 and 2 do not support these two assumptions. First, 2 million new hires spread over 10 years is not an abnormally high level for teaching. The latter is one of the largest occupations (U.S. Bureau of the Census, 1998) and, numerically there are large teacher flows into schools each year. For instance, about 245,000 new entrants were hired by schools for the 2003-04 year alone. Second, the data do not support the assumption that there is an alarming underproduction of new teachers. Overall, the data show there is a sufficient number of new teachers supplied to replace losses due to both retirement and nonretirement factors.

\section{Local and national labor markets}

Of course, an adequate or inadequate national supply does not necessarily mean there is an adequate or inadequate local supply. Indeed, educational analysts have long held that elementary/secondary teaching has a highly localized labor market, in contrast to, for instance, the national labor market for professors in higher education with. In turn, a widely believed variant of the teacher shortage thesis holds that teacher shortages are not national, but are geographically based. From this view, shortages are a result of an uneven production of new

teachers across states and locales. Some states and locales produce sufficient numbers of new teachers, while others do not. Moreover, in this view, barriers to cross-state and cross-district movement exacerbate these geographically based shortages (e.g., National Commission on Teaching, 1997; Murphy et al., 2004). The factors that impede cross-district and cross-state teacher hiring and mobility include a lack of pension portability, nontransferability and 
nonreciprocity of licensing/certification across states, a lack of assistance with candidates' moving expenses, and district-based salary schedule systems that force experienced teachers to accept pay reductions when moving (e.g., Curran et al., 2001; Darling-Hammond, 2001; State Higher Education Executive Officers Association, 2004).

Moreover, in addition to these structural barriers, there is a self-selection factor. A number of studies have shown that those entering teaching tend to prefer to teach in schools like those they themselves attended and, hence, seek teaching jobs close to home (e.g., Boyd et al., 2005; Loeb \& Reininger, 2004). The result of these factors, analysts argue, is that the teacher supply is unevenly distributed and the supply available for one district or state is not necessarily available for others.

However, data from various sources raise questions for this geographically based teacher shortage thesis. First, there are indications that teaching is increasingly developing a regional and even national labor market. The National Association for State Directors of Teacher Education and Certification (NASDTEC) has brokered teaching license and certification reciprocity across 45 states. Federal legislation such as NCLB and national advanced certification initiatives, such as the National Board for Professional Teaching Standards (NBPTS), have promoted broader cross-state standards for teacher preparation and licensing. Despite barriers, many states hire a large proportion of their new teachers from out of state. For example, federal data collected under Title II legislation indicate that in 2003-04 over a quarter of applicants for teaching jobs across the nation were from out-of-state candidates. In almost one third of the states-Alaska, Colorado, Delaware, Minnesota, Kansas, Maryland, North Carolina, Nevada, West Virginia, Virginia, North Dakota, New Hampshire, South Carolina, and Wyoming - more than one third of the teaching job applications were from candidates certified in other states (Barnes, 2006). In short, the degree to which the teacher labor market is local, regional, or national varies.

Second, the degree to which requirements are deemed overly burdensome barriers is relative. Teaching is not the only occupation with state-based licensure and entry requirements. For example, bar exams in the law profession are partly state based and attorneys moving out of state usually are required to pass an exam in the new state before being allowed to practice. It is unclear to what extent these requirements decrease cross-state mobility of attorneys. However, 
the law profession in general does not suffer from labor supply shortages; indeed, it is often referred to as a surplus field. Labor economics theory suggests that the extent to which the requirements for cross-state mobility are, or are not, considered overly burdensome largely depends on the attractiveness of the job and occupation. In other words, the crux of the issue is the ratio between requirement and rewards, and between costs and benefits, in a given occupation. Even time-consuming and financially costly requirements for cross-state occupational mobility could be deemed acceptable by candidates, if the benefits and rewards of a job are held to be sufficient.

The data suggest that the ratio between benefits and costs varies in the teaching occupation. The above Title II data indicate that some schools, in some school districts, in some states clearly have been successful in attracting candidates from a regional or national labor market; others less so. Moreover, even in the same state and locale, and hence, ostensibly within the same teacher labor market, and within the same licensure and pension system, the extent of staffing problems can vary greatly among different types of schools. Some observers have noted, for example, that in the same metropolitan area in the same year, some schools have extensive waiting lists of qualified candidates for their teaching job openings while other nearby schools have great difficulty filling their teaching job openings with qualified candidates (e.g., National Commission on Teaching, 1997; Liu et al. 2008). ${ }^{7}$

Hence, it is true that both the production of new teachers and school staffing problems are not evenly distributed across locales, and moreover there are costs to cross-locale mobility. However, because some locales have staffing problems does not necessarily mean they suffer from shortages in the sense that too few new teachers are produced in their pipeline. Rather, the data suggest the source of shortages is the relative ability, or inability, of particular schools to attract and retain sufficient numbers of the available supply of teachers, from both the pipeline and the reserve pool, and from both in-state and out-of-state. All of this suggests that school staffing problems, and apparent imbalances between supply and demand, must be examined from

7. Consistent with this, we have found in an analysis of variance of the SASS data that the variation in reported school hiring difficulties and staffing problems is significantly greater within, rather than between, states. Using a one-way random effects ANOVA model, the data show that the variance component within states was 44 times the size of the variance component between states. Intraclass correlation $=.022$. 
a school and organizational-level perspective to be fully understood.

\section{What Is the Role of Teacher Turnover in School Staffing Problems?}

In addition to levels and adequacies of the new teacher supply, the data in Table 2 illuminate two other important points. First, the data suggest that the demand for new teachers, and accompanying staffing problems, are linked to teacher attrition. For instance, at the beginning of the 1999-2000 year, about 232,000 teachers entered, or reentered, teaching (Rows 1:A:i + B:i + B:ii), but by the following school year, about 278,000 (Row 3:B)—equivalent to $120 \%$ of those just hired-left teaching.

For science, those leaving teaching at the end of the year represented $130 \%$ of those who entered at the beginning of that year. For mathematics, at the beginning of the 1999-2000 year, about 11,300 new mathematics teachers entered teaching, but by the following school year, 13,750 — again equivalent to about $120 \%$ of those just hired—left teaching.

Second, although teacher retirements have increased in recent years, as shown in table 1, they account for only a small portion of the above total turnover. For example, at the end of the $1999-2000$ year there were about 67,000 retirees, accounting for only $24 \%$ of the 277,605 leavers and only $12 \%$ of the total turnover of 546,247 during that period. This has been fairly consistent: Across the five cycles of SASS/TFS from 1988 to 2004, retirement represented 12\%-14\% of total turnover in any given year (see table 1, Row: 4:A). Likewise, for mathematics and science, retirement also accounts for a relatively small portion of total turnover.

We further empirically tested this link between teacher turnover and school staffing difficulties. The majority of secondary schools, as shown earlier in Figure 2, do not experience serious difficulties filling their openings with qualified mathematics and science candidates. We found that those schools that do report difficulties filling their openings are almost twice as likely, and at a statistically significant level, to have above-average turnover rates as those schools reporting no difficulties.

Average annual total turnover rates for teaching have been relatively stable in recent years: $14.5 \%$ in $1988-89 ; 13.2 \%$ in $1991-92 ; 14.3 \%$ in $1994-95 ; 15.7 \%$ in $2000-01 ; 16.2 \%$ in 2004- $05^{8}$ (See Figure 4). Total teacher departures are fairly evenly split between the two general

8. Note: The 2000-01 rates in Figure 4 slightly differ from those derived by dividing Row 3 by Row 2 in Table 2 because 
types of total turnover we have examined-movers and leavers. As mentioned earlier, from an organizational perspective it is important to count both teacher migration and attrition because they equally contribute to a school's staffing needs and problems. Notably, mathematics and science teachers do not on average have significantly higher rates of turnover than do English teachers.

It is important to recognize that teaching is one of the largest occupations, and as a result, these flows of teachers in and out of schools are numerically large. As shown in Table 2, over 535,000 teachers newly entered schools at the beginning of the 1999-2000 school year; by the following year a larger number — about 546,000 teachers - moved from or left their schools. In other words, during that period there were over 1 million job transitions, representing almost one third of this relatively large occupational force. Among these were over 100,000 job transitions for mathematics and science teachers alone, representing almost one third of the mathematics/science teaching force.

Figure 4: Percent Annual Teacher Turnover, by Field and by Year

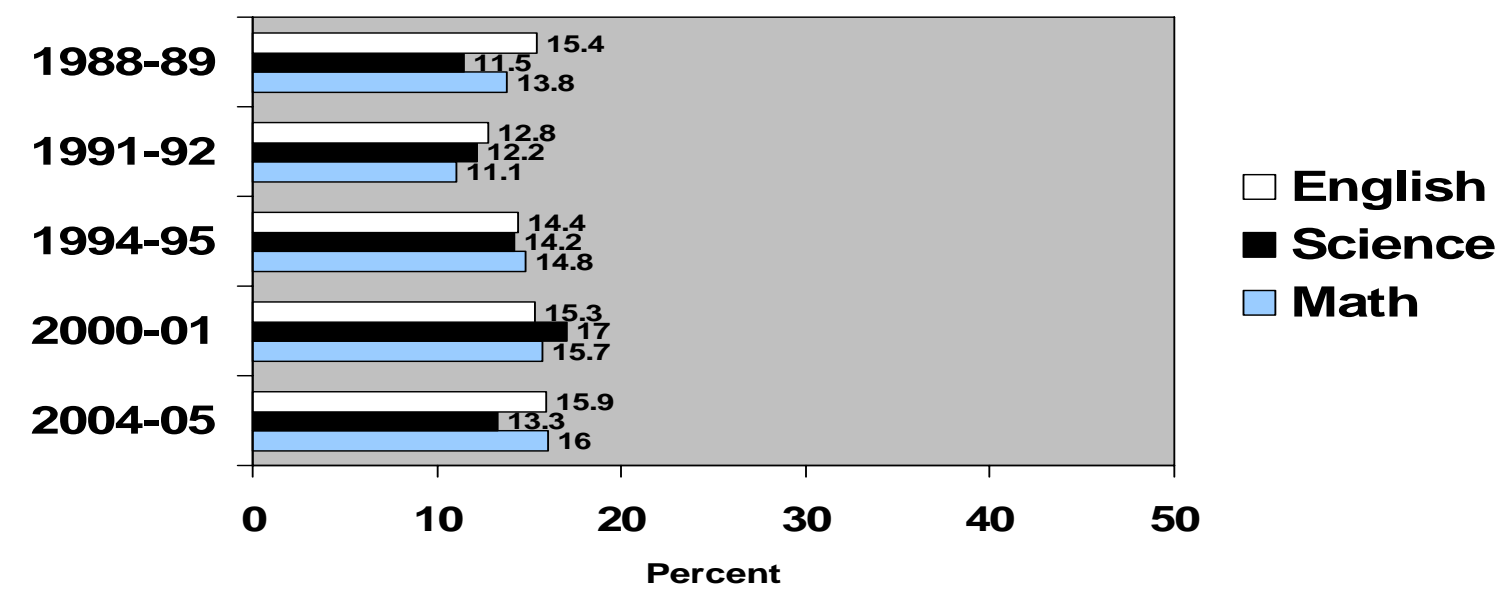

Source: Teacher Followup Survey 
One question that naturally arises concerns how these rates of teacher turnover compare to employee turnover rates in other occupations and lines of work. In recent re-analyses of the $1993 \mathrm{~B} \& \mathrm{~B}$, and using other data, we have found that, as one might expect, teaching has far higher annual turnover than some higher-status or higher-pay occupations (such as lawyers, engineers, architects, professors), about the same as other mid-status occupations (police, nurses), and less turnover than some lower-status lines of work (child care workers, secretaries). We closely examine these issues in a second related paper (see Ingersoll \& Perda, 2009). From the organizational perspective of the present study, the important empirical question is not whether teaching has higher or lower turnover than other occupations, but rather is teacher turnover a problem for schools themselves.

There can be numerous costs and benefits, advantages and disadvantages to teacher turnover. Here the data reveal one consequence - the teacher shortage. The data show that most of the hiring of new mathematics and science teachers is simply to fill spots vacated by other math and science teachers who departed at the end of the prior school year. And, most of these departures are not a result of a "graying workforce.” Rather, preretirement turnover is a primary factor behind the demand for hew hires and the accompanying difficulties schools have adequately staffing classrooms with qualified math and science teachers.

\section{What Are the Sources of Teacher Turnover?}

The data also show the flows of teachers out of schools are not equally distributed and that rates of turnover vary greatly among different kinds of schools. We have undertaken adjusted multivariate regression analyses using the SASS/TFS data to estimate the relationships between a variety of school demographic characteristics and the likelihood of individual teachers moving from or leaving their schools (for detailed reports, see Ingersoll, 2001; Smith \& Ingersoll, 2004; and Ingersoll \& May, 2009). We found that school poverty, school size, and the urbanicity of the school community were among the school demographic characteristics most correlated with teacher turnover in public schools. To illustrate the range of annual teacher turnover rates among a variety of different kinds of schools, we used the resulting coefficients to estimate the predicted probabilities of turnover for various combinations of school characteristics 
(e.g., small/not-poor/suburban; large/urban/poor, etc.). ${ }^{9}$ These probabilities are displayed in Figure 5. On one end of the continuum lie larger, low-poverty, suburban public schools that have, on average, $11 \%$ annual turnover. On the other end of the continuum lie smaller, urban, high-poverty public schools with over double that rate. These data raise the questions-why do some schools have far higher turnover than others? What are the sources of teacher turnover?

Figure 5: Predicted Probabilities of Public School Teacher Turnover, by Selected School Characteristics (2000-2001)

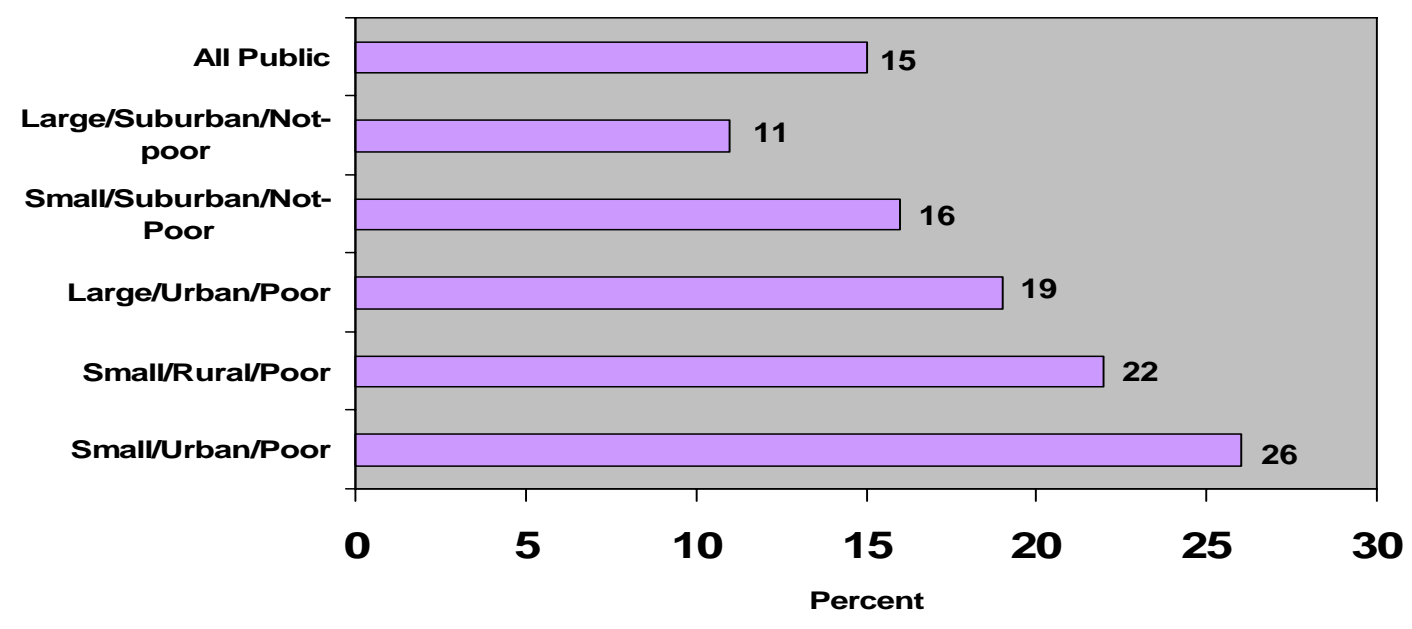

One method of answering this question is to ask those who have moved and left why they did so. We examined such self-report data drawn from items in the TFS questionnaire that asked teachers to indicate from a list provided in the survey questionnaire the most important reasons for their migration or attrition. Figure 6 presents data on the percentage of teachers who reported that particular categories of reasons were "very" or "extremely" important in their decision to depart on a five-point scale from "not important" to "extremely important." Note that the percentages in Figure 6 add up to more than 100\%, because respondents could indicate more

9. In Figure 5, we defined large schools as those with 600 or more students and small schools as those with fewer than 300 students. High-poverty refers to schools with a poverty enrollment of $80 \%$ or more; low-poverty refers to schools with a poverty enrollment below $10 \%$. 
than one reason for their departures and hence our categories are not mutually exclusive. ${ }^{10}$

Overall, mathematics/science teachers are both similar and different from other teachers in the general patterns regarding the reasons why they move from or leave their jobs. Consistent with the earlier data we reported in Tables 1 and 2, retirement is not an especially prominent factor in overall turnover. Retirement was listed by only about $13 \%$ of the total of those who departed as important in their decision to depart. School staffing cutbacks due to layoffs, terminations, school closings, and reorganizations, like retirement, account for only a relatively small portion of total turnover from schools - and less than $7 \%$ for mathematics and science. These staffing actions more often result in migration to other teaching jobs than in leaving teaching altogether.

A third category of turnover - that for family or personal reasons-includes departures for pregnancy, child rearing, health problems, and family moves. These account for more turnover, and at a statistically significant level, than either retirement or staffing actions. These reasons are also probably common to all occupations and all types of organizations. Mathematics and science teachers cite these as reasons for their departures at a slightly greater, and statistically significant, level than other teachers do.

10. From a list of 17 reasons, we created five categories, as follows: (1) Retirement; (2) School Staffing Action: reduction-in-force/layoff/involuntary transfer; (3) Family or Personal: change of residence; pregnancy/child rearing; health; other family or personal reason; take sabbatical; (4) To Pursue Other Job: teach in another state, but certificate not accepted there; to pursue another career; to take courses to improve career opportunities within or outside the field of education; felt job security higher at another school; opportunity for better teaching assignment at another school; (5) Dissatisfaction: dissatisfied with job; for better salary or benefits; school received little support from community; not agree with, or not feel prepared to implement, new reforms; dissatisfied with workplace conditions; lack of support from administration; lack of autonomy; lack of professional development. 


\section{Figure 6: Percent Teachers Reporting Various Sets of Reasons}

for Their Turnover, by Field (2000-2001)

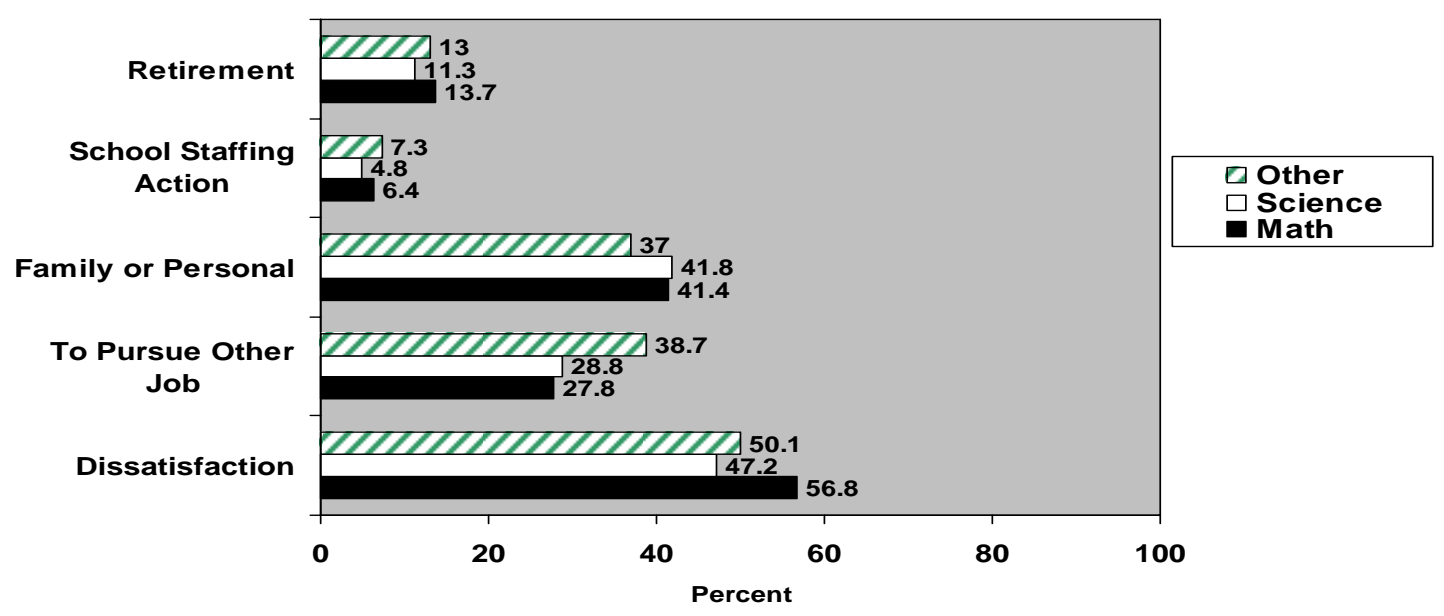

Finally, two related categories of reasons are, collectively, a very prominent source of turnover and are directly related to the occupational and organizational conditions of teaching job changing and dissatisfaction. Individually, each of these categories accounts for more turnover, and at a highly statistically significant level, than does retirement. Combined, these are the most prominent set of reasons teachers report for their turnover. Over half of all departures report as a reason either job dissatisfaction or the desire to pursue a better job, or another career, or to improve career opportunities in or out of education. Surprisingly, mathematics and science teachers less frequently than other teachers, and again at a statistically significant level, report that their departures were due to the pursuit of another career, to moves to other schools in or out of their state, or to take courses to improve career opportunities within or outside the field of education. $^{11}$

Using figures from Table 2 and the above self-reports, the data show that of the 13,750 mathematics teachers who left teaching between the 1999-2000 and 2000-01 school years, about 8,000 reported that job dissatisfaction was "very" or "extremely important" in their decision to

11. Among these are job shifters who leave the classroom to take positions in the larger field of education. For an insightful analysis of these flows, see Quartz, et al. 2008. 
leave. In contrast, only about 3,900 of the 13,750 who left reported that retirement was a similarly important factor in their decision to leave. Table 2 also indicates that about 8,000 new mathematics teachers were produced in the pipeline that year. In other words, the new teacher supply pipeline alone was more than sufficient to replace losses due to retirement that year, but the pipeline alone was barely sufficient to replace the larger portion of attrition due to dissatisfaction.

These data raise a further question: What are the most important sources of dissatisfaction among those who moved from or left their teaching jobs? From a list of factors in the TFS, those who departed were asked to indicate which factors were a source of job satisfaction or dissatisfaction. Table 3 presents the 14 highest percentages of those who indicated that they "somewhat" or "strongly" agreed (on a five-point scale from "strongly agree" to “strongly disagree”) that a factor was a source of dissatisfaction, by field. Among mathematics teachers, over half reported they agreed that salary and/or benefits were inadequate or poor. Among science teachers, the percentage who reported they agreed that salary and/or benefits were inadequate or poor was lower. The SASS data indicate that in 2003-2004, the average starting salary in public schools for a teacher with a bachelor's degree and no experience was about \$32,000, and the average maximum salary (the highest offered by the school to any teacher) was about $\$ 61,000$. Average starting and maximum salaries in private schools were significantly lower.

In addition, among mathematics teachers, inadequate preparation time, lack of teacher influence over decision-making, too little opportunity for professional advancement, and inadequate computers and technology were the most frequently cited sources of dissatisfaction. Among science teachers, inadequate preparation time, lack of teacher influence over decisionmaking, class sizes, and inadequate computers and technology were the most frequently cited factors. Note that the data do not indicate that these factors were the issues that led to teacher departures; the data simply indicate the numbers of departed teachers who reported dissatisfaction with these issues at their prior school. From an organizational perspective, these sources are all notable because they are examples of manipulable and policy-amenable aspects of particular districts and schools. 
Table 3. Of Those Teachers Who Moved From or Left Their School, Percent Reporting They Agreed That Various Factors Were a Source of Dissatisfaction, by Field. (2000-2001).

\begin{tabular}{|c|c|c|c|}
\hline Source of Dissatisfaction & Other (\%) & Science $(\%)$ & Math (\%) \\
\hline Poor Salary or Benefits & 60 & 46.3 & 59.9 \\
\hline Student Behavioral Problems & 48.9 & 45.6 & 42.4 \\
\hline Poor Student Motivation & 27.7 & 27.4 & 33.5 \\
\hline Too Little Support From Parents & 37.1 & 26.5 & 35.4 \\
\hline Class Sizes Too Large & 50.3 & 50.9 & 44.9 \\
\hline Too Heavy Teaching Load & 56.5 & 43 & 43.4 \\
\hline Lack of Faculty Influence and Autonomy & 48.8 & 61.5 & 53.7 \\
\hline Insufficient Computers and Technology & 42 & 48.7 & 45.1 \\
\hline Inadequate Time to Plan and Prepare & 62 & 69.3 & 67.5 \\
\hline Too Little Time for Collaboration & 35.9 & 35.8 & 44.3 \\
\hline Too Many Interruptions of Teaching Time & 37.6 & 36.9 & 35.5 \\
\hline Difficulties Due to Mainstreaming Special Students & 35 & 44 & 32.5 \\
\hline Too Little Opportunity for Prof 'l Advancement & 39 & 42.6 & 46.2 \\
\hline
\end{tabular}


Self-report data such as in Figure 6 and Table 3 are useful because those departing are, of course, often in the best position to know the reasons for their departures and which aspects of their schools were and were not sources of satisfaction or dissatisfaction. But, such self-report data also are retrospective attributions, subject to bias, and hence warrant caution in interpretation. In other projects we have followed up our descriptive analyses of the TFS selfreport data with detailed multivariate regression analyses of the larger SASS/TFS sample to estimate the associations between a range of organizational conditions and the likelihood of individual teachers departing, while controlling for teacher and school characteristics. We have done such analyses both for all teachers (Ingersoll, 2001) and specifically for mathematics and science teachers (Ingersoll \& May, 2009). In general, we have found the results of the regression models to be consistent with the findings from the self-report data, lending confidence to both sets of results. Moreover, we have found these general patterns to be fairly consistent across different types and cycles of the data, across different kinds of schools, and across different subsets of teacher turnover.

\section{Conclusions and Implications}

Almost without exception, it is widely believed that the nation is facing a teacher shortage crisis, especially for mathematics and science, resulting primarily from an insufficient production of new teachers. It is also widely held that the mathematics/science teacher shortage is a major factor behind inadequate educational performance and, in turn, the well-being of the economy and even the security of the nation.

The data presented in this analysis do not support the mathematics/science teacher shortage thesis. The data show that there are indeed widespread school staffing problems; that is, many schools experience difficulties filling their classrooms with qualified candidates. The data also show that the severity of these problems varies across schools and fields. In 1999-2000, about 7,200 or $31 \%$ of secondary schools reported they had serious difficulty finding qualified teachers to fill either their mathematics or science openings.

But, contrary to conventional wisdom, the data also show that these school staffing problems are not simply due to the production of too few new teachers. During the 1999-2000 
school year, about 22,000 newly qualified mathematics and science teachers were produced in the new teacher supply pipeline from preparation programs. This was $2 \frac{1}{2} 2$ times the number of mathematics and science teachers to retire at the end of that same year. When we factor in new hires from the reserve pool of former teachers and delayed entrants, the ratio of supply to retirement is even higher. This finding is further reinforced because our data sources are downward biased and provide underestimates of the new teacher supply.

However, a different picture emerges when we include preretirement losses of teachersa figure that is many times larger than losses due to retirement and a primary factor driving demand for new hires. Mathematics and science teachers have about the same annual rates of turnover as other teachers. But unlike, for instance, the case of English teachers, the educational system does not enjoy an overwhelming surplus of new mathematics and science teachers relative to total turnover. For the field of English, the supply of new teachers from the pipeline and the reserve pool is more than sufficient to replace all losses, due to either retirement or other reasons. For mathematics and science, there is a much tighter balance between the new teacher supply and total turnover, including both retirement and other reasons. The supply of new teachers from the pipeline and the reserve pool is barely sufficient, with just over one new mathematics or science teacher for each mathematics or science teacher who leaves teaching.

The data also show teacher turnover is not evenly distributed. There are large variations in turnover within states and large school-to-school differences in turnover. Moreover, these differences are tied to the attractiveness of the working conditions in schools. While less than a quarter of all mathematics and science teachers who left teaching at the end of the 1999-2000 year did so because of retirement, about half of their attrition was tied to job dissatisfaction. The data show that replacing attrition losses linked to job dissatisfaction accounted for $98 \%$ of the new mathematics teachers and 74\% of the new science teachers in the pipeline in 1999-2000. In other words, demand for new math and science hires and attendant staffing problems are largely a result of preretirement turnover, and a significant portion of the latter is driven by job dissatisfaction.

From the framework of economic theory, an imbalance between teacher demand and supply can technically be referred to as a shortage, in the sense that there is an inadequate 
quantity of qualified teachers who are able and willing to offer their services at a given wage and given working conditions in given schools. However, in the context of teachers and schools, the term shortage has come to almost always connote an insufficient production of new teachers in the face of high levels of teacher retirements. In turn, reforms typically emphasize increases in the production and recruitment of new teachers. Rarely have commentators or researchers considered the impact of preretirement turnover on these imbalances. These diagnostic and terminological distinctions have crucial implications for prescription and policy.

The theory of supply and demand holds that where the quantity of teachers demanded is greater than the quantity of teachers supplied given the prevailing wages and conditions, there are two basic policy approaches-increase the quantity supplied or decrease the quantity demanded. As noted in the beginning of this article, increased teacher production and recruitment have been, and continue to be, the dominant strategies to addressing school staffing inadequacies. Of the many examples of this approach, one strategy that has been less emphasized - yet is suggested by our data analysis - is to further tap into the large reserve pool of former teachers.

However, production and recruitment alone do not address a major source of the problem. The data indicate that there are sufficient numbers of qualified teachers, but not significant numbers of willing teachers. This analysis indicates that demand for new hires and the subsequent staffing problems are largely a result of preretirement turnover. Hence, this analysis suggests that recruitment programs alone will not solve the staffing problems of schools, if they do not also address the issue of teacher retention. In short, this analysis suggests that recruiting more teachers will not solve staffing inadequacies if large numbers of such teachers then leave teaching long before retirement. Again, the turnover of mathematics and science teachers is an especially important issue to address because these fields do not have the same large “cushion” of new teacher supply enjoyed by fields such as English. For example, President Bush pledged in his 2006 State of the Union speech to recruit 30,000 new mathematics and science teachers in the nation. However, the data indicate that over 35,000 mathematics and science teachers left teaching just after the 1999-2000 school year alone. Only about 8,000 of these left because of retirement. Almost 18,000 indicated that job dissatisfaction was a major 
factor in their decision to leave.

What alternative policy prescriptions are suggested by this analysis? From the perspective of this analysis, schools are not simply victims of inexorable demographic trends, and there is a significant role for the management of schools in both the genesis of, and solution to, school staffing problems. In addition to increasing the quantity of new teacher supply, this analysis also suggests the need to decrease turnover. The data suggest that a key way to improve teacher retention is to improve the conditions of the teaching job. In our research, we have found that schools with more support for new teachers, more generous salary schedules, fewer student discipline problems, more adequate resources and classroom supplies, more effective leadership, and enhanced faculty input into school decision-making —all have significantly lower levels of teacher turnover (Ingersoll, 2001; Smith \& Ingersoll, 2004; Ingersoll \& May, 2008). The data suggest that changing these conditions would contribute to lower rates of turnover, which would, in turn, diminish school staffing problems and, hence, as widely believed, ultimately aid the performance of schools. 


\section{References}

American Association for Employment in Education. (2008). Educator Supply and Demand in the United States. Columbus, OH: Author.

Barnes, G., Crowe, E., \& Schaefer, B. (2007). The cost of teacher turnover in five school districts. Washington, DC: National Commission on Teaching and America's Future.

Barnes, N. (2006). Promoting teacher mobility through license reciprocity: What is being done. Unpublished Master's Thesis, University of Pennsylvania.

Baron, J., \& Bielby, W. (1980). Bringing the firm back in: Stratification, segmentation, and the organization of work. American Sociological Review, 45, 737-765.

Boe, E., \& Gilford, D. (1992). Teacher supply, demand and quality. Washington, DC: National Academy Press.

Boyd, D., Lankford, H., Loeb, S., \& Wyckoff, J. (2005). The draw of home: How teachers' preferences for proximity disadvantage urban schools. Journal of Policy Analysis and Management, 24(1), 113-132.

Chandler, K., Luekens, M., Lyter, D., \& Fox, E. (2004). Teacher attrition and mobility: Results from the teacher follow-up survey, 2000-01. Washington, DC: National Center for Education Statistics.

Curran, B., Abrahams, C., \& Clarke, T. (2001). Solving teacher shortages through license reciprocity. Denver, CO: State Higher Education Executive Officers Association.

Darling-Hammond, L. (1984). Beyond the commission reports: The coming crisis in teaching. Santa Monica, CA: RAND.

Darling-Hammond, L. (2001). The challenge our schools face. Educational Leadership, 58, 12-17.

Etzioni, A. (Ed.) (1969). The semi-professions and their organizations: Teachers, nurses and social workers (pp. 1-53). New York: Free Press.

Feistritzer, E. (1997). Alternative teacher certification: A state-by-state analysis (1997). Washington, DC: National Center for Education Information.

Gerald, D., \& Hussar, W. (1998). Projections of education statistics to 2008. Washington, DC: National Center for Education Statistics.

Grissmer, D., \& Kirby, S. (1992). Patterns of attrition among Indiana teachers, 1965-1987. Santa Monica, CA: RAND.

Grissmer, D., \& Kirby, S. (1997). Teacher turnover and teacher quality. Teachers College Record, 99, 45-56.

Henke, R., Chen, X., \& Geis, S. (2000). Progress through the pipeline: 1992-93 college graduates and elementary/secondary school teaching as of 1997. Washington, DC: National Center for Education Statistics.

Hirsch, E., Koppich, J., \& Knapp, M. (2001). Revisiting what states are doing to improve the quality of teaching: An update on patterns and trends. Seattle, WA: Center for the Study of Teaching and Policy, University of Washington.

Hom, P., \& Griffeth, R. (1995). Employee turnover. Cincinnati, OH: South-Western.

Hussar, W. (1998). Predicting the need for newly hired teachers in the United States to 200809. Washington, DC: National Center for Education Statistics.

Ingersoll, R. (2001). Teacher turnover and teacher shortages: An organizational analysis. American Educational Research Journal, 38(3), 499-534. 
Ingersoll, R. (2003). Is there really a teacher shortage? Philadelphia, PA, and Seattle, WA: Consortium for Policy Research in Education, University of Pennsylvania, and the Center for the Study of Teaching and Policy, University of Washington.

Ingersoll, R. (2004). Four myths about America's teacher quality problem. In M. Smylie \& D. Miretzky (Eds.), The $103^{\text {rd }}$ yearbook of the National Society for the Study of Education, (pp. 1-33). Chicago: University of Chicago Press.

Ingersoll, R. (2007). A comparative study of teacher preparation and qualifications in 6 nations. Philadelphia: Consortium for Policy Research in Education.

Ingersoll, R., \& Perda, D. (2008). The status of teaching as a profession. In J. Ballantine \& J. Spade (Eds.), Schools and society: A sociological approach to education, (pp. 107-118) . Los Angeles: Pine Forge Press.

Ingersoll, R., \& Perda, D. (2009). How high is teacher turnover and is it a problem? Manuscript in preparation.

Ingersoll, R., \& May, H. (2009). The determinants of mathematics and science teacher turnover. Manuscript in preparation.

Liu, E., Rosenstein, J., Swann, A., Khalil, D. 2008. When Districts Encounter Teacher Shortages? The Challenges of Recruiting and Retaining Math Teachers in Urban Districts. Leadership and Policy in Schools. 7(3): 296-323.

Loeb, S., \& Reininger, M. (2004). Public policy and teacher labor markets. East Lansing, MI: The Education Policy Center at Michigan State University.

Lortie, D. (1975). School teacher. Chicago: University of Chicago Press.

Mobley, W. (1982). Employee turnover: Causes, consequences and control. Reading, MA: Addison-Wesley.

Mueller, C., \& Price, J. (1990). Economic, psychological and sociological determinants of voluntary turnover. Journal of Behavioral Economics, 19, 321-335.

Murnane, R., Singer, J., Willett, J., Kemple, J., \& Olsen, R. (1991). Who will teach? Policies that matter. Cambridge, MA: Harvard University Press.

Murphy, P., DeArmond, M., \& Guin, K. (2004). A national crisis or localized problems? Getting perspective on the scope and scale of the teacher shortage. Education Policy Analysis Archives, 11(23). Available at http://epaa.asu.edu/epaa/v11n23/.

National Academy of Sciences. (1987). Toward understanding teacher supply and demand. Washington, DC: National Academies Press.

National Academy of Sciences. (2006). Rising above the gathering storm. Washington, DC: National Academies Press.

National Commission on Excellence in Education. (1983). A nation at risk: The imperative for educational reform. Washington, DC: Government Printing Office.

National Commission on Mathematics and Science Teaching for the 21st Century (the Glenn Commission). (2000). Before it's too late. Washington, DC: Government Printing Office.

National Commission on Teaching and America's Future. (1997). Doing what matters most: Investing in quality teaching. New York: National Commission on Teaching and America’s Future.

National Education Association. (2001). Status of the American public school teacher survey. Washington, DC: Author. 
NCES (National Center for Education Statistics). (2004). 2000-2001 Baccalaureate and beyond survey (B\&B). Data File. Washington, DC: U.S. Department of Education. Available from http://nces.ed.gov/surveys/b\&b/

NCES (National Center for Education Statistics). (2003). Integrated postsecondary educational data system (IPEDS). Data File. Washington, DC: U.S. Department of Education. Available from http://nces.ed.gov/ipeds/

NCES (National Center for Education Statistics). (2005). Schools and staffing survey (SASS) and teacher followup survey (TFS). Data File. Washington, DC: U.S. Department of Education. Available from http://nces.ed.gov/surveys/SASS/

National Research Council. (2002). Learning and understanding: Improving advanced study of mathematics and science in U.S. schools. Washington, DC: National Academies Press.

Price, J. 1977. The study of turnover. Ames, IA: Iowa State University Press.

Price, J. 1989. The impact of turnover on the organization. Work and Occupations, 16, 461473.

Quartz, K., Thomas, A., Anderson, L., Masyn, K., Lyons, K., Olsen, B. 2008. Careers in Motion: a Longitudinal Study of Role Changing Patterns Among Urban Educators. Teachers College Record. 110.

Rice, J., Roellke, C., Sparks, D., \& Kolbe, T. (2008). Piecing together the teacher policy landscape: A policy-problem typology. Teachers College Record. Available at http://www.tcrecord.org/Content.asp?ContentId=15223

Smith, T., \& Ingersoll, R. (2004). What are the effects of induction on beginning teacher turnover? American Educational Research Journal, 41, 681-714.

State Higher Education Executive Officers Association (SHEEO). (2004). Teacher quality initiative. Denver: Author.

Stolzenberg, R. (1978). Bringing the firm back in: Employer size, employee schooling and socioeconomic achievement. American Sociological Review, 43, 813-28.

Strauss, R., Tucci, T., \& Yang, J. (2008, March). The market demand for teachers and the financial position of state-supported teacher preparation institutions in Pennsylvania. Paper presented at the Annual Meeting of the American Educational Research Association, New York.

Tyack. D. (1974). The one best system. Cambridge, MA: Harvard University Press.

U.S. Bureau of the Census. (1998). The statistical abstract (117th ed.). Washington, DC: U.S. Department of Commerce.

U.S. Department of Education. 2002. Meeting the highly qualified teachers challenge: The secretary's annual report on teacher quality. Washington, DC: Author.

U.S. Department of Education. 2008. Teacher Shortage Areas Nationwide Listing 1990-91 to 2007-08. Washington, DC: Author.

Villar, A. (2004, April). Measuring the benefits and costs of mentor-based induction. Paper presented at the Annual Meeting of the American Educational Research Association, San Diego.

Weaver, T. (1983). America's teacher quality problem: Alternatives for reform. New York: Praeger.

Weiss, I. R., \& Boyd, S. E. (1990). Where are they now? A follow-up study of the 1985-86 science and mathematics teaching force. Chapel Hill, NC: Horizon Research. 


\section{Nondiscrimination Statement}

The University of Pennsylvania values diversity and seeks talented students, faculty, and staff from diverse backgrounds. The University of Pennsylvania does not discriminate on the basis of race, sex, sexual orientation, religion, color, national or ethnic origin, age, disability, or status as a Vietnam Era Veteran or disabled veteran in the administration of educational policies, programs, or activities; admissions policies, scholarships, or loan awards; athletic, or Universityadministered programs or employment. Questions or complaints regarding this policy should be directed to Executive Director, Office of Affirmative Action, 1133 Blockley Hall, Philadelphia, PA 19104-6021 or 215-898-6993 (Voice) or 215-898-7803 (TDD). 